\title{
Pig based production system contributing towards the sustainable livelihood of the tribes of Jharkhand
}

\author{
MUKESH KUMAR, JANCY GUPTA, APARNA RADHAKRISHNAN AND MINU SINGH
}

\begin{abstract}
The present study was conducted in two randomly selected districts of Jharkhand. The study assessed the extent of Pig Based Production System Contributing towards the Sustainable Livelihood of the tribes in the Govindpur and Ormanjhi blocks of Dhanbad and Ranchi districts, respectively from 2013- 14. The data was solicited from 120 randomly selected households and the study was conducted through personal interviews of the selected respondents in the villages selected by random sampling technique, personal observations and participatory rural appraisal techniques i.e. transect walk, social mapping, key informant interview, focus group discussions. The results indicated that the livelihoods of tribal communities in the area have traditionally been dominated by the pig based production system- $\mathrm{C}+\mathrm{G}+\mathrm{P}$. Among the sustainable livelihood components human capital was minimum compared to others and use of traditional knowledge (5.88), education of family members (5.98), ICT tools (5.95) and use of natural resources (5.71) had highest influence on sustainable livelihood of the respondents. The pig production system prevalent in the area were found to be substantially contributing for the sustainable livelihood of the respondents and were the integral part of day-to-day livelihood activities, nutritional security and traditional life style for tribal people in the area $(\mathrm{C}=$ Cattle, $\mathrm{G}=\mathrm{Goat}, \mathrm{P}=\mathrm{Pig})$.
\end{abstract}

KEY WORDS : Pig production systems, Sustainable livelihood, Tribes

HOW TO CITE THIS PAPER : Kumar, Mukesh, Gupta, Jancy, Radhakrishnan, Aparna and Singh, Minu (2015). Pig based production system contributing towards the sustainable livelihood of the tribes of Jharkhand. Res. J. Animal Hus. \& Dairy Sci., 6(1) : 27-31. 